\title{
Spirometra Mansonoides em fezes de felino doméstico no município de Pelotas, RS, Brasil, relato de caso
}

Spirometra Mansonoides é um Cestódeo da família Diphyllobothriidae, agente responsável pela zoonose parasitária denominada Esparganose. Acomete o intestino delgado de diversos mamíferos, como cães e gatos, seus hospedeiros definitivos (HD), e também o homem. Possui dois hospedeiros intermediários (HI), o crustáceo copépode $(10 \mathrm{HI})$, que pode ser ingerido pelo $20 \mathrm{HI}$, como repteis, anfíbios e peixes. O HD geralmente infecta-se pela ingestão do $20 \mathrm{HI}$ contendo larvas pleurocercóides em seus tecidos. O diagnóstico pode ser realizado através de exame coproparasitológico, onde a técnica de sedimentação é bastante eficaz para visualização dos ovos. $\mathrm{O}$ objetivo deste trabalho é relatar um caso de felino doméstico infectado por Spirometra sp. evidenciando o diagnóstico deste parasito.

Palavras-chave: Cestódeo; Gatos; Diagnóstico.

\section{Spirometra mansonoides in feces of domestic feline in the municipality of Pelotas, RS, Brazil, case report}

Spirometra Mansonoides is a Cestode of the family Diphyllobothriidae, an agent responsible for zoonosis called Esparganose. It affects the small intestine of several mammals, such as dogs and cats, their definitive hosts (HD), and also man. It has two intermediate hosts ( $\mathrm{HI})$, the copepod crustacean (10 HI), which can be ingested by the $20 \mathrm{HI}$, such as reptiles, amphibians and fish. $\mathrm{HD}$ is usually infected by ingesting the $20 \mathrm{HI}$ containing pleurocercoid larvae in its tissues. The diagnosis can be made through coproparasitological examination, where the sedimentation technique is very effective for visualizing the eggs. The objective of this work is to report a case of a domestic cat infected by Spirometra sp. evidencing the diagnosis of this parasite.

Keywords: Cestode; Cats; Diagnosis.

Alexsander Ferraz (iD)

Universidade Federal de Pelotas, Brasil http://lattes.cnpq.br/5047550122468432 http://orcid.org/0000-0002-0424-6249 xanderferraz@yahoo.com.br

Bruna dos Santos Pires (iD

Universidade Federal de Pelotas, Brasil http://lattes.cnpq.br/2019874644735527 http://orcid.org/0000-0002-3755-6243 bruspires@gmail.com

Eugênia Tavares Barwaldt (iD

Universidade Federal de Pelotas, Brasil http://lattes.cnpq.br/4970989236096941 http://orcid.org/0000-0002-4902-1203 tbeugenia@gmail.com

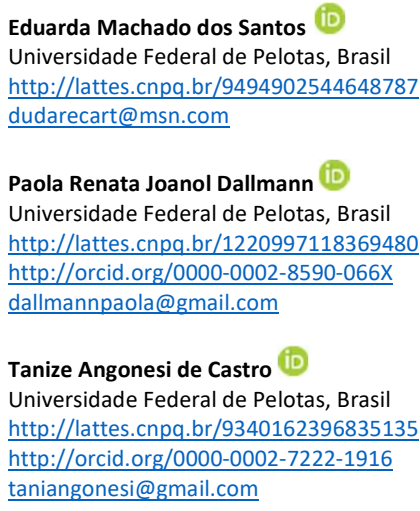

Eduarda Machado dos Santos (iD)

Universidade Federal de Pelotas, Brasil

http://lattes.cnpq.br/9494902544648787 dudarecart@msn.com

Paola Renata Joanol Dallmann

Universidade Federal de Pelotas, Brasil

http://lattes.cnpq.br/1220997118369480

http://orcid.org/0000-0002-8590-066X

dallmannpaola@gmail.com

Tanize Angonesi de Castro

Universidade Federal de Pelotas, Brasil

http://lattes.cnpq.br/9340162396835135

http://orcid.org/0000-0002-7222-1916

taniangonesi@gmail.com

Márcia de Oliveira Nobre

Universidade Federal de Pelotas, Brasil

http://lattes.cnpq.br/3741542973280238

http://orcid.org/0000-0003-3284-9167

marciaonobre@gmail.com

Leandro Quintana Nizoli (iD)

Universidade Federal de Pelotas, Brasil

http://lattes.cnpq.br/3556266527587195

http://orcid.org/0000-0002-0767-4097

leandro.nizoli@gmail.com
6

DOI: 10.6008/CBPC2236-9600.2020.001.0002
Referencing this:

FERRAZ, A.; PIRES, B. S.; BARWALDT, E. T.; SANTOS, E. M.; DALLMANN, P. R. J.; CASTRO, T. A.; NOBRE, M. O.; NIZOLI, L. Q.. Spirometra Mansonoides em fezes de felino doméstico no município de Pelotas, RS, Brasil, relato de caso. Scire Salutis, v.10, n.1, p.10-13, 2020. DOI: http://doi.org/10.6008/CBPC2236-9600.2020.001.0002 


\section{INTRODUÇÃO}

Spirometra Mansonoides é um Cestódeo da família Diphyllobothriidae, que acomete o intestino delgado, principalmente de cães e gatos, podendo parasitar também o homem, pois apresenta potencial zoonótico (TANTALEAN et al., 2005). No seu ciclo biológico, inicialmente, os hospedeiros definitivos eliminam ovos não embrionados nas fezes para o ambiente. Na água, os ovos tornam-se embrionados e formam o coracídeo, este tem capacidade natatória, pois possui cílios vibráteis que lhe permite nadar na água.

O coracídeo vai ser ingerido pelo primeiro hospedeiro intermediário, geralmente um crustáceo copépode, e transforma-se em larva procercóide (WONGKULAB et al., 2011). Esse crustáceo, contendo a larva procercóide no interior do seu intestino, pode ser ingerido pelo segundo hospedeiro intermediário, como repteis, anfíbios e peixes (SCHOLZ et al., 2009). As procercóides penetram no trato intestinal e se transformam em larvas plerocercóides (ou espargano), que migram para os tecidos e músculos subcutâneos (ANANTAPHRUTI et al., 2011).

Os hospedeiros definitivos, geralmente, infectam-se ao ingerir o segundo hospedeiro intermediário, contendo a larva plerocercoide e esta, em torno de 20 dias se transforma em parasito adulto no intestino delgado do hospedeiro definitivo (SCHOLZ et al., 2009; WONGKULAB et al., 2011). As formas adultas realizarão postura de ovos, que serão eliminados com as fezes no ambiente, dando início novamente ao ciclo biológico deste cestódeo (SOUZA et al., 2014).

As infecções causadas por Spirometra sp., geralmente são assintomáticas, porém alguns estudos sugerem associação entre este gênero de parasito com quadros de diarreia, perda de peso e lesões intestinais em felinos (UGARTE et al., 2005). O objetivo deste trabalho, foi relatar um caso de Spirometra sp. em felino doméstico, evidenciando o diagnóstico coproparasitológico deste parasito.

\section{RELATO}

A amostra recebida no Laboratório de Doenças Parasitárias da Faculdade de Veterinária da Universidade Federal de Pelotas, foi procedente de um felino, fêmea, adulto, SRD. Os tutores relataram que o animal apresentava há algumas semanas, fezes amolecidas, evoluindo para diarreia nos últimos dias. Foi informado ainda, que a gata tinha acesso à rua em breves períodos do dia.

A amostra foi analisada através das seguintes técnicas: Willis-Mollay (1921), que utiliza o princípio da flutuação de ovos leves de helmintos e oocistos em solução hipersaturada; Faust et al. (1938), técnica de centrifugo flutuação em solução de sulfato de zinco a 33\%, utilizada para pesquisa de cistos de Giardia spp. e oocistos e técnica de Hoffmann et al. (HPJ) (1934) que consiste na sedimentação espontânea de ovos pesados, como dos cestódeos e trematódeos. As análises foram realizadas em microscopia óptica com aumento de 100 e 400x e a identificação dos gêneros de parasitos foi realizada a partir das características morfológicas dos ovos. 


\section{RESULTADO}

Após análise do material, foi observado, através das técnicas de Willis-Mollay e de Hoffmann, a presença de ovos de Spirometra sp. (Figura 1). Estes possuem como características morfológicas, serem operculados, de cor castanho escuro, elípticos e com polos assimétricos, um mais afilado e outro arredondado, medindo aproximadamente $60 \times 44$ micras. 0 tratamento preconizado para eliminar o parasito foi praziquantel $(7,5 \mathrm{mg} / \mathrm{kg})$, dois dias consecutivos. Após o tratamento, foi solicitado nova amostra de fezes, onde constatou-se a eficácia do mesmo.

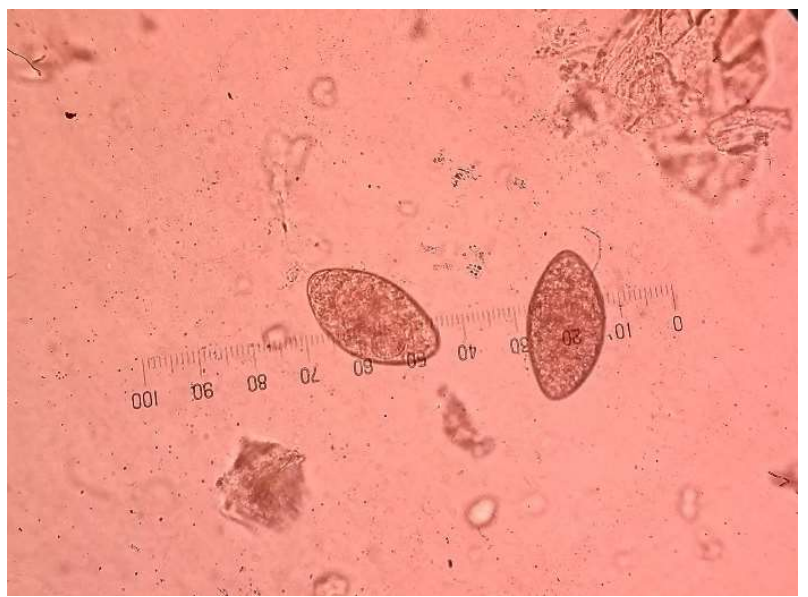

Figura 1: Ovos de Spirometra sp. em amostra fecal de um felino doméstico, observados em microscopia óptica, aumento de 400x.

Apesar da Spirometra sp. ser pouco identificada e relatada no sul do Brasil, alguns estudos demostram a presença de ovos deste parasito através de técnicas coproparasitológicas, como o de Marques et al. (2019), que diagnosticaram, através das mesmas técnicas do nosso estudo, a presença de $S$. mansonoides em seis gatos domésticos e um gato maracajá em Porto Alegre, RS. Em Santa Maria, RS, Dall'Agnol et al. (2010) analisando amostras fecais de 116 gatos domiciliados no referido município, observaram que 2,6\% destas (3/116), continham ovos deste gênero de parasito. Em Porto Alegre, RS, um caso de felino doméstico, parasitado com S. mansonoides, em uma coinfecção com o ectoparasito Demodex cati.

Animais com acesso à rua, assim como o felino deste relato, apresentam maior risco de infecção, pois podem ingerir algum dos hospedeiros intermediários contendo larvas pleurocercóides na musculatura. Portanto, a presença destes hospedeiros, é fator determinante para a manutenção do ciclo deste parasito (LIU et al., 2015). Em humanos, a Esparganose tem sido relatada principalmente na Ásia, devido aos hábitos alimentares tradicionais da sua população, dentre os quais estão a ingestão de serpentes, sapos e rãs, potenciais hospedeiros intermediários (HUGHES et al., 2002)

O diagnóstico deste parasito, pode ser realizado pela deteç̧ão de ovos nas fezes, através de técnicas coproparasitologicas de flutuação e de sedimentação, embora seja relatado que a sedimentação apresente melhores resultados (CONBOY, 2009). No nosso relato, foi possível observar ovos de Spirometra sp. após execução de ambas as técnicas. 


\section{CONSIDERAÇÕES FINAIS}

A partir deste relato e de outros estudos que citam a presença de Spirometra em amostras de fezes de cães e gatos, conclui-se que este gênero de parasito pode ter sua prevalência subestimada nestas espécies. Portanto, faz-se necessário a realização de técnicas apropriadas para pesquisa de ovos deste agente, além de medidas preventivas, como evitar acesso dos animais a rua e contato com os hospedeiros intermediários, bem como manter o cronograma de vermifugação atualizado e realizar exames coproparasitológicos periodicamente.

\section{REFERÊNCIAS}

ANANTAPHRUTI, M.T.; NAWA, Y.; VANVANITCHAI, Y.. Human sparganosis in Thailand: an overview. Acta Tropica, v.118, n.3, p.171-176, 2011

CONBOY, G.. Cestodes of dogs and cats in North America. Veterinary Clinics: Small Animal Practice, v.39, .6, p.10751090, 2009.

DALL'AGNOL, L. P.; OTTO, M. A.; SILVA, A. S.; MONTEIRO, S. G.. Parasitos gastrintestinais em gatos naturalmente infectados no município de santa maria no estado do rio grande do sul, brasil. Acta Veterinária Brasílica, v.4, n.3, p.181-184, 2010.

FAUST, E. C.; D'ANTONI, J. S.; ODOM, V.. A critical study of clinical laboratory technics for the diagnosis of protozoan cysts and helminth eggs in feces I. Preliminary communication. American Journal of Tropical Medicine, v.18, p.169-183, 1938.

HOFFMAN, W. A.; PONS, J. A.; JANER, J. L.. Sedimentation concentration method in Schistosomiasis mansoni. The Puerto Rico Journal of Public Health and Tropical Medicine, v.9, p.283-298, 1934.

HUGHES, A. J.; BIGGS, B. A.. Parasitic worms of the central nervous system: an Australian perspective. Internal Medicine Journal, v.32, n.11, p.541-553, 2002.

LIU, Q.; LI, M. W.; WANG, Z. D.; ZHAO, G. H.; ZHU, X. Q.. Human sparganosis, a neglected food borne zoonosis. The
Lancet Infectious Diseases, v.15, n.10, p.1226-1235, 2015.

MARQUES, S. M. T.; SCISLESKI, M. S. O.; SOUZA, A. L.; MURARI, C. R.. Spirometra mansonoides (Cestoda: Diphyllobothriidae) nas fezes de felídeos atendidos em Porto Alegre/RS: Um parasito negligenciado. Pubvet, v.13, n.4, p.14, 2019.

SCHOLZ, T.; GARCIA, H. H.; KUCHTA, R.; WICHT, B.. Update on the Human Broad Tapeworm (Genus Diphyllobothrium), Including Clinical Relevance. Clinical Microbiology Reviews, v.22, p.146-160, 2009.

TANTALEAN, M.; MICHAUD, C.. Huésped definitivo de Spirometra mansonoides (Cestoda, Diphyllobothriidae) en el Perú. Rev. Vet. Biol., v.12, n.1, p.153-157, 2005.

UGARTE, C. E.; THOMAS, D. G.; GASSER, R. B.; HU, M.; SCOTT, I.; COLLETT, M. G.. Spirometra erinacei/S. erinaceieuropaei in a feral cat in Manawatu with chronic intermittent diarrhoea. New Zealand Veterinary Journal, v.53, n.5, p.347-351, 2005.

WILLIS-MOLLAY, H. H.. A simple levitation method for the detection of hookworm ova. The Medical Journal Australia, v.2, n.18, p.375-376, 1921.

WONGKULAB, P.; SUKONTASON, K.; CHAIWARITH, R.. Sparganosis: a brief review. Journal of Infectious Diseases and Antimicrobiological Agents, v.28, p.77-80, 2011.

A CBPC - Companhia Brasileira de Produção Científica (CNPJ: 11.221.422/0001-03) detém os direitos materiais desta publicação. Os direitos referem-se à publicação do trabalho em qualquer parte do mundo, incluindo os direitos às renovações, expansões e disseminações da contribuição, bem como outros direitos subsidiários. Todos os trabalhos publicados eletronicamente poderão posteriormente ser publicados em coletâneas impressas sob coordenação da Sustenere Publishing, da Companhia Brasileira de Produção Cientifica e seus parceiros autorizados. Os (as) autores (as) preservam os direitos autorais, mas não têm permissão para a publicação da contribuição em outro meio, impresso ou digital, em português ou em tradução. 